\title{
Knowledge and attitudes of family physicians coming to COPD continuing medical education
}

\author{
Barbara P Yawn \\ Peter C Wollan
}

Olmsted Medical Center, Research Department, Rochester, MN, USA

Correspondence: Barbara Yawn

Olmsted Medical Center, Research

Department, 210 Ninth Street. SE,

Rochester, MN 55904, USA

Tel + I 5072872758

Fax +I 5072872722

Email yawnx002@umn.edu
Purpose: COPD remains under-recognized and under-treated. Much of early COPD care is given by primary care physicians but only when COPD is recognized. This survey explores the attitudes, beliefs, and knowledge related to COPD recognition, diagnosis, and treatment from family physicians and nurse practitioners (NPs) and physician assistants (PAs) working in primary care.

Methods: We completed a survey of family physicians, and NPs/PAs attending one of three CME programs on five common chronic conditions including COPD.

Results: Return rate was $62 \%(\mathrm{n}=284)$ including 178 physicians and 100 NPs/PAs. Fewer than half of the respondents reported knowledge of or use of COPD guidelines. The barriers to recognition and diagnosis of COPD they reported included the multiple morbidities of most COPD patients, failure of patients to report COPD symptoms, as well as lack of knowledge and inadequate training in COPD diagnosis and management. Three quarters $(74 \%)$ of respondents reported use of spirometry to diagnose COPD but only 32\% said they included reversibility assessment. COPD was incorrectly assessed as a disease primarily of men (78\% of respondents) that appeared after age $60(61 \%)$. Few respondents reported that they believed COPD treatment was useful or very useful for improving symptoms (15\%) or decreasing exacerbations $(3 \%)$ or that pulmonary rehabilitation was helpful (3\%), but 13\% reported they thought COPD treatment could extend longevity.

Conclusions: Primary care physicians and NPs/PAs working in primary care continue to report lack of awareness and use of COPD guidelines, as well as correct information related to COPD epidemiology or potential benefits of available treatments including pulmonary rehabilitation. It is unlikely that diagnosis and management of COPD will improve in primary care until these knowledge gaps and discrepancies with published efficacy of therapy issues are addressed.

Keywords: COPD treatment, diagnosis, management, patients, family physicians

\section{Introduction}

Primary care physicians provide all or at least part of the health care for $80 \%$ of the more than 20 million Americans with recognized and unrecognized chronic obstructive pulmonary disease (COPD) (Mannino 2002; GSK 2007). For those with recognized COPD, current management is frequently incompatible with recommended care (ATS 2004; GOLD 2007; NICE 2007) For those who have unrecognized COPD, opportunities to improve their functional status, quality of life, and prevention of exacerbations are missed by failure to recognize the disease (Pena et al 2000; Halbert et al 2003, 2006; Zaas et al 2004; Lindberg et al 2006).

Among the barriers that may slow the implementation of evidence-based COPD management are ambiguous and divergent US recommendations for COPD screening (NLHEP 1998; Hardie et al 2002; Bolton et al 2005; Wilt et al 2005; Hansen-Flaschen 2007; Yawn et al 2007). The lack of well recognized US primary care guidelines for the management of diagnosed COPD is another potential barrier to an aggressive primary care approach to COPD. The international Global Initiative for Obstructive 
Lung Disease (GOLD) guidelines (GOLD 2007; Hurst and Wedzicha 2007), the International Primary Care Respiratory Group (IPCRG) COPD guidelines (Levy et al 2006), and the American Thoracic Society/European Respiratory Society COPD guidelines (ATS/ERS 2004) have received limited exposure among US primary care physicians, especially in comparison with guidelines for the other major obstructive lung disease, asthma.

As part of its effort to collaborate with the National Heart Lung and Blood Institute's (NHLBI) COPD public awareness campaign (GOLD 2007), the American Academy of Family Physicians (AAFP) included COPD as part of its annual clinical focus on five chronic diseases in 2006-2007 and sponsored COPD continuing medical education (CME) sessions in three major US cities in the summer of 2006. In conjunction with those sessions, COPD-related surveys were distributed to all attendees. Information from these surveys was used to better focus future education programs and as a comparison for similar data from generalists practicing in other countries such as the United Kingdom and the Netherlands where COPD management has received greater primary care emphasis (Mulcahy et al 2005; Meulepas et al 2006).

\section{Methods}

The attendees of three AAFP sponsored CME programs held in Raleigh, NC, Costa Mesa, CA and Chicago, IL were asked to complete a brief survey during the 10 minutes immediately prior to a 70-min talk on COPD diagnosis and management given by one of the authors (BPY). The completed surveys were collected during the first 15 minutes of the talk so that little of the information in the talk should have influenced the attendees' responses to the surveys. We therefore believe that the information provided is based on attendees' prior knowledge of COPD, not on knowledge gained during the lecture.

The overall response rate to the survey varied slightly by site from 155 (70\%) in Chicago, to 170 (55\%) in Costa Mesa, and 130 (57\%) in Raleigh. The total number of useable surveys was 284 out of 455 possible ( $62 \%$ overall).

The survey included questions on demographic information: specialty, age (divided into 5 categories), gender, and length of time in practice (in 4 categories). Additional practice-related information included: practice site (rural/ urban/suburban), practice size (solo, small group - up to 5, medium -6 to 10 and over 10 ), and practice type (single or multi-specialty).

Specific questions about COPD included queries about which guidelines the respondent used for COPD, barriers to
COPD diagnosis, characteristics used to make a diagnosis of COPD and testing done for COPD. Two questions about rates of smoking in patients in the community and access to smoking cessation services were included.

The last set of questions asked about attitudes and beliefs related to COPD including differentiation from asthma, effectiveness of treatment for COPD symptoms, increasing longevity, decreasing exacerbations and the value and accessibility of pulmonary rehabilitation. The final two questions addressed the expected gender and age of symptom-onset of COPD patients.

Data were entered into an Excel (Microsoft, Redmond, WA) spreadsheet and first analyzed using simple descriptive statistics to obtain frequencies of responses overall. Responses were stratified in different groupings including by site of program (eg, region of country, $n=3$ ), and by level of training (physician versus nurse practitioner [NP] and physician's assistant [PA]). Statistical comparisons used chi-square and Mantel Haenzel testing. Regression models were developed for use of spirometry testing for diagnosis of COPD that included respondent's age, gender, level of training, region of country, and time since graduating as the independent variables. Similar models were developed for use of reversibility testing and use of COPD guidelines.

\section{Results}

The attendee respondents whose data were included in the analysis $(\mathrm{n}=278)$ were a combination of family physicians ( $\mathrm{n}=178,63 \%$ of respondents), and nonphysician clinicians including NPs and PAs $(\mathrm{n}=100,35 \%)$. Four respondents identified themselves as "other" and two others who did not answer the question were excluded from further analysis. The median age was 40-49 years and over half (57\%) were women (Table 1).

The most commonly reported "COPD" guidelines used were the GOLD and ATS/ERS guidelines $(n=133,47 \%$, either one or both). Sixty two people (21\%) reporting using none and $27(10 \%)$ stated that they did not know such guidelines existed. Thirty one people (11\%) checked that they used the NAEPP guidelines for COPD. These are asthma guidelines that do not deal with COPD. Lack of awareness of COPD guidelines (didn't know, plus those reporting use of NAEPP guidelines for COPD) varied by site of the talk, the qualifications of the health professional, their age, and whether or not they had spirometry equipment in their office (Table 2).

Respondents were asked to mark all barriers they experience in diagnosing COPD. The most commonly listed 
Table I Demographics

\begin{tabular}{lll}
\hline $\begin{array}{l}\text { Type of health } \\
\text { professional }\end{array}$ & $\begin{array}{l}\text { Medical } \\
\text { doctor }\end{array}$ & $\begin{array}{l}\text { Nurse practitionerl } \\
\text { Physician's assistant }\end{array}$ \\
\hline Median age & $50-59$ & $40-49$ \\
$\%$ women & $42 \%$ & $86 \%$ \\
Median tears in practice & $16-25$ & $5-15$ \\
Had spirometry in office & $55 \%$ & $55 \%$ \\
$\begin{array}{l}\text { Used reversibility or post } \\
\text { bronchodilator testing }\end{array}$ & $38 \%$ & $23 \%$ \\
$\begin{array}{l}\text { for diagnosis } \\
\text { Reports lack of }\end{array}$ & \\
knowledge as a barrier & $39(22 \%)$ & $33(33 \%)$ \\
\hline
\end{tabular}

barriers to the diagnosis of COPD are shown in Table 3 and include lack of symptoms, failure of patient to report symptoms as well as the impact of multiple chronic conditions in people with COPD. About one in four respondents admitted to inadequate knowledge and training about COPD diagnosis and management. Some perceived barriers such as the presence of multiple morbidities (NP/PAs (64\%) vs MDs (45\%); $\mathrm{p}=0.01)$ and lack of training (NPs/PAs $33 \%$ vs M.D. $(22 \%)$; $\mathrm{p}=0.06$ ) varied by level of health professional (Table 4).

Frequently reported barriers also varied by region of the country. Attendees in Chicago were significantly less likely to report patient failure to report symptoms (37\%) compared with attendees in Costa Mesa, CA and Raleigh, NC (54\% and 55\%, respectively; $p=0.01)$. Concerns about training were more common among attendees from Costa Mesa, CA (35\%) than among those from Raleigh, NC (21\%) $(p=0.01)$. However, reported use of spirometry did not vary by region (Table 2 ).

While a history of smoking, cough, and dyspnea were all considered important in diagnosing COPD, spirometry testing results was the most commonly listed factor for diagnosing COPD (Table 3). While $76 \%$ of the attendees stated that they used spirometry for COPD diagnosis and 52\% $(n=148)$ said they had spirometry testing available in their office, only $31 \%(n=89)$ said they used spirometry for all COPD diagnoses. Only 91 (32\%) respondents (38\% of MDs vs $23 \%$ of NPs/Pas; $p=0.01$ ) reported use of reversibility testing for COPD diagnosis (See Table 2).
Other "tests" used for diagnosing COPD included chest $\mathrm{x}$-ray, a trial of bronchodilators and a trial of oral steroids (Table 2). One in five, 56 (20\%) reported referring all or most COPD patients to a lung specialist. Nineteen of the 278 (7\%) reported regular use of alpha-one antitrypsin levels in testing COPD patients.

About one third of the attendees reported that the differentiation between asthma and COPD was difficult $(\mathrm{n}=108$, $38 \%$ ) while over three-quarters, $78 \%$, stated that COPD was primarily a disease of men and over half (61\%) said that the COPD generally started at or after age 60 .

While only $6 \%$ of the respondents reported that "lack of adequate treatment for COPD" was a barrier to diagnosis of COPD, few were optimistic about the value of COPD treatments. Overall, 15\% stated that COPD treatment was somewhat or very useful for improving symptoms, and 3\% thought that treatment was useful or very useful for decreasing the risk of exacerbations yet 13\% stated that they thought COPD treatment could increase longevity. Beliefs about the value of COPD treatments did not vary significantly by site or training level.

Pulmonary rehabilitation was available to $32 \%$ of the attendees but only 3\% thought rehabilitation was useful or very useful for COPD patients with another $16 \%$ saying they are neutral about the benefits of pulmonary rehabilitation. Beliefs about the value of pulmonary rehabilitation did not vary by site although pulmonary rehabilitation services had significantly higher availability for respondents in Costa Mesa, CA and Chicago, IL than in Raleigh, NC (32\% and $28 \%$ vs $5 \%$, respectively, $p=0.01$ ).

Use of GOLD or ATS/ERS guidelines, use of bronchodilator reversibility or spirometry testing in COPD diagnosis were examined for associations with demographic and office characteristics through multivariable logistic regression. Few associations were found. In particular, no significant associations were found with age, gender, experience, size of practice, or size of local population. MD's were more likely than NP/ PAs to use bronchodilator reversibility in diagnosis $(\mathrm{OR}=2.1$, $\mathrm{p}=0.005)$. Spirometry was more likely to be used in diagnosis when the office had a spirometer $(\mathrm{OR}=3.7, \mathrm{p}<0.0001)$.

Table 2 Use of guidelines with respondent characteristics

\begin{tabular}{llllll}
\hline $\begin{array}{l}\text { Type of health } \\
\text { professional }\end{array}$ & $\begin{array}{l}\text { Medical doctor } \\
\mathbf{n = 1 7 8}\end{array}$ & $\begin{array}{l}\text { Nurse practitionerl } \\
\text { Physician's assistant } \mathbf{n = 1 0 0}\end{array}$ & $\begin{array}{l}\text { Has spirometry } \\
\text { in office } \mathbf{n = 1 4 8}\end{array}$ & $\begin{array}{l}\text { Age }<\mathbf{5 0} \\
\mathbf{n = 1 4 9}\end{array}$ & $\begin{array}{l}\text { Age } \geq \mathbf{5 0} \\
\mathbf{n = 1 3 0}\end{array}$ \\
\hline $\begin{array}{l}\text { Uses GOLD or ATS COPD } \\
\text { guidelines }\end{array}$ & $56(31 \%)$ & $34(34 \%)$ & $62(42 \%)$ & $47(32 \%)$ & $42(32 \%)$ \\
\begin{tabular}{l} 
Uses none or does not know \\
\hline
\end{tabular} & $59(33 \%)$ & $40(40 \%)$ & $43(29 \%)$ & $59(40 \%)$ & $42(45 \%)$ \\
\hline
\end{tabular}


Table 3 Use of signs and symptoms and tests to diagnose COPD

\begin{tabular}{llllllll}
\hline $\begin{array}{l}\text { Type of } \\
\text { training }\end{array}$ & Spirometry & $\begin{array}{l}\text { Pre and post } \\
\text { broncho-dilator }\end{array}$ & $\begin{array}{l}\text { Symptoms } \\
\text { (any of three) }\end{array}$ & $\begin{array}{l}\text { Smoking } \\
\text { history }\end{array}$ & $\begin{array}{l}\text { Chest } \\
\text { radiograph }\end{array}$ & $\begin{array}{l}\text { Trial of } \\
\text { corticosteroids }\end{array}$ & $\begin{array}{l}\text { Trial of } \\
\text { broncho-dilators }\end{array}$ \\
\hline MD $n=178$ & $138(78 \%)$ & $56(31 \%)$ & $120(67 \%)$ & $118(66 \%)$ & $109(61 \%)$ & $22(12 \%)$ & $56(31 \%)$ \\
NP/PA $n=100$ & $74(74 \%)$ & $23(23 \%)$ & $61(61 \%)$ & $59(59 \%)$ & $59(59 \%)$ & $7(7 \%)$ & $23(23 \%)$ \\
\hline
\end{tabular}

Abbreviations: MD, medical doctor; NP, nursing practitioner; PA, physician's assistant.

And GOLD or ATS guidelines were more likely to be used when the office had a spirometer $(\mathrm{OR}=2.4, \mathrm{p}=0.002)$.

\section{Discussion}

The health professionals attending these conferences report that almost half of them used either the GOLD or ATS/ERS guidelines for COPD diagnosis and management. Most of the other attendees ( $40 \%$ ) were unaware of any COPD care guidelines or stated that they used the NAEPP (asthma) guidelines for COPD management. Even without use of guidelines, almost three-quarters of the attendees stated they used spirometry to diagnosis COPD with only about one third reporting inclusion of pre- and post-bronchodilator testing to make the diagnosis. This suggests that two-thirds do not consider lack of reversibility a necessary criteria for COPD diagnosis. This is comparable with awareness of COPD guidelines but higher reported COPD guideline and spirometry use than reported by Barr and colleagues (2005).

The attendees expressed considerable pessimism in the ability of medical therapy to improve symptoms or prevent exacerbations. Yet $15 \%$ felt that COPD therapy could improve longevity. These results suggest significant opportunities for education and improvements in use of tools to improve COPD recognition and management.

The reported use of spirometry among these attendees was higher than has been reported among family physicians in previous studies (Fauzi 2003; Dowd et al 2003; DiazLobato et al 2004; Caramori et al 2005; Fried et al 2005; Kaminsky et al 2005; Walters et al 2005; Lusuardi et al 2006). It is possible that this is due to the large metropolitan communities in which these presentations were given, the presence of nonphysician clinicians who worked in specialty departments in primary care offices or to an increase acceptance of the value and importance of spirometry over the past 5 to 8 years. Several recent publications have supported the availability and positive impact of spirometry testing in family or general practices (Nihlen et al 2003; Schermer et al 2003; Buffels et al 2004; Bolton et al 2005; Walker et al 2006; Tinkelman et al 2007; Yawn et al 2007). Since COPD was only one of five topics covered during these day-long sessions, it seems illogical to assume that all attendees had a special interest in COPD.

Less than half of the physicians and other clinicians who say they use spirometry to diagnose COPD reported they included reversibility or post bronchodilation assessment in the diagnostic evaluation. This is not consistent with COPD guidelines that list the lack of significant reversibility as a hallmark and part of the definition of COPD (ATS 2004; GOLD 2007; Hurst and Wedzicha 2007).

About half of the physicians and other clinicians expressed concern that their patients fail to report COPD-related symptoms even though most respondents said they used symptoms of dyspnea with activity or at rest to diagnose COPD. This concern echoes that of other physicians around the world. To deal with this concern, several questionnaire-based COPD screening tools have been developed and tested in general practice patients (Freeman et al 2005; van Schayck et al 2005; Price et al 2006). Most of these surveys query patients about chronic productive cough, shortness of breath with exercise, increasing exercise intolerance, and smoking behavior. The need for these questionnaires is based on the premise that patients are often not forth-coming about symptoms and that without tools physicians and other clinicians often fail to ask

Table 4 Perceived barriers in the diagnosis of COPD

\begin{tabular}{lllllll}
\hline $\begin{array}{l}\text { Type of } \\
\text { health professional }\end{array}$ & $\begin{array}{l}\text { Lack of specific } \\
\text { symptoms }\end{array}$ & $\begin{array}{l}\text { Failure of patients } \\
\text { to recognize } \\
\text { and report dyspnea }\end{array}$ & $\begin{array}{l}\text { Multiple } \\
\text { chronic } \\
\text { conditions }\end{array}$ & $\begin{array}{l}\text { Lack of } \\
\text { knowledge } \\
\text { and training }\end{array}$ & $\begin{array}{l}\text { Lack of } \\
\text { access to } \\
\text { spirometry }\end{array}$ & $\begin{array}{l}\text { Lack of } \\
\text { effective } \\
\text { treatment }\end{array}$ \\
\hline MD $n=178$ & $35(20 \%)$ & $85(48 \%)$ & $80(45 \%)$ & $39(22 \%)$ & $51(29 \%)$ & $13(7 \%)$ \\
NP/Pas $n=100$ & $22(22 \%)$ & $50(50 \%)$ & $64(64 \%)$ & $33(33 \%)$ & $21(21 \%)$ & $5(5 \%)$ \\
\hline
\end{tabular}

Abbreviations: MD, medical doctor; NP, nursing practitioner; PA, physician's assistant. 
about specific symptoms (Freeman et al 2005; van Schayck et al 2005; Garcia-Aymerich et al 2006; Price et al 2006). The recent and ongoing NHLBI public awareness campaign is also based on this premise and uses many formats and types of media to help raise awareness of symptoms that patients should report to their physician or other clinician (see www.COPD-medications. gov, www.COPD-guidebook.gov).

The depth of the pessimism about the outcome of COPD treatment was disappointing. Primary care physicians often report cases of patients diagnosed with COPD whom the physician was unable to "help" except with terminal illness planning. Although some pessimism may be appropriate, it was surprising and inconsistent with reported data, that over $84 \%$ of health care professionals reported that they felt pharmacotherapy had no effect on COPD symptom reduction or reduction of exacerbations (Appleton et al 2000; Calverley 2000; Van Noord et al 2000; Pauwels et al 2001; Barnes 2002; Anzueto et al 2005; Cazzola et al 2005; Kesten and O'Donnel 2005; Calverley et al 2007). In addition, the attitude toward and use of pulmonary rehabilitation was very low. While availability was limited (32\% reported availability) use was even lower. Recent data clearly shows the benefits of pulmonary rehabilitation (Paz-Diaz et al 2007; Ries et al 2007; Birnbaum and Carlin 2008). Additionally, education regarding the components and benefits of pulmonary rehabilitation and better reimbursement opportunities for these services could increase its inclusion in COPD management by primary care physicians. Conversely, the $15 \%$ of respondents who reported that COPD improved longevity may be over-optimistic. The optimism might be explained by attendees including smoking cessation and oxygen therapy in their group of COPD treatments that increase longevity (Anthonisen et al 1994).

COPD is not a disease of men and often begins before age 60 , unlike the beliefs expressed by over $60 \%$ of the attendees. Beginning in 2000, more women than men die each year of COPD (Buist et al 2007; Mannino and Buist 2007) and COPD often begins in the patient's 40 s or 50 s. Early symptoms may go unnoticed including the early changes in activity levels and exertion that are the adaptations made to deal with early COPD (Chavannes et al 2004; Freeman et al 2005; Levy et al 2006; Price et al 2006; GOLD 2007; Hurst and Wedzicha 2007; USPSTF 2007). The clinicians' misperceptions again suggest opportunities for education and potentially changes who and how patients are assessed for COPD.

A significant percent of the attendees recognized and reported a gap in their training about the diagnosis and management of COPD. Training related to COPD and its diagnosis through use of pre- and post-bronchodilator spirometry testing should begin in medical school (Yawn and Yawn 2005) and be supplemented in residency training and in continuing medical education. Physicians who had completed training within the past 15 years were no more likely than those completing training more than 15 year ago to report use of spirometry or reversibility testing to diagnose COPD, which suggests that more recent training is still not addressing this issue sufficiently. The ability to fit additional COPD training into the more limited training time available to NPs and PAs will require very careful consideration of their role in COPD management.

This study is not large. However, the results are comparable to those of previous larger studies of US physicians (Barr et al 2005). The generalizability of the results are limited by the inclusion of only 3 geographic sites and by the $37 \%$ of attendees who did not return the survey. It is also possible that the attendees had a special interest in COPD. However, this seems unlikely since COPD was only one of five chronic diseases covered during the one day session. Generalizability from the full sample may also be limited by the large number of non-physician clinicians in attendance, a percent significantly higher than in US clinic practice. For example, NP/PAs were less likely than physicians to report using reversibility testing in making the diagnosis of COPD.

In summary, COPD is the fourth leading cause of death in the US and among the top 10 reasons patients visit a family physician. While the data from this survey is encouraging in the rate of reported use of spirometry testing for COPD diagnosis, awareness of COPD guidelines and pessimism regarding the benefits of treating COPD, the infrequent use of reversibility testing for COPD diagnosis, and the over $40 \%$ of attendees who do not use and are not even aware of COPD guidelines should be the basis for a review of our medical and nursing education regarding COPD during initial training and in continuing education programs.

\section{References}

[ATS/ERS] American Thoracic Society, European Respiratory Society. 2004. Standards for the diagnosis and care of patients with chronic obstructive pulmonary disease [online]. Accessed December 9, 2005. URL: http://www-test.thoracic.org/copd/.

Anthonisen N, Connett J, Kiley J, et al. 1994. Effects of smoking intervention and the use of an inhaled anticholinergic bronchodilator on the rate of decline of FEV1: the Lung Health Study. JAMA, 272:1497-505.

Anzueto A, Tashkin D, Menjoge S, et al. 2005. One-year analysis of longitudinal changes in spirometry in patients with COPD receiving tiotropium. Pulm Pharmacol Ther, 18:75-81.

Appleton S, Smith B, Veale A, et al. 2000. Long-acting b2-agonists for chronic obstructive pulmonary disease. Cochrane Database Syst Rev, 2:CD001104. 
Barnes PJ. 2002. New treatments for COPD. Nat Rev Drug Discov, 6:437-46.

Barr RG, Celli BR, Martinez FJ, et al. 2005. Physician and patient perceptions in COPD: the COPD Resource Network Needs Assessment Survey. Am J Med, 118:1415.

Birnbaum S, Carlin B. 2006. Pulmonary rehabilitation and respiratory therapy services in the physician office setting. Chest, 129:169-73.

Bolton C, Ionescu A, Edwards P, et al. 2005. Attaining a correct diagnosis of COPD in general practice. Respir Med, 99:493-500.

Buffels J, Degryse J, Jeyrman J, et al. 2004. Office spirometry significantly improves early detection of COPD in general practice. The DIDASCO Study. Chest, 125:1394-9.

Buist AS, McBurnie MA, Vollmer WM, et al. 2007. International variation in the prevalence of COPD (the BOLD Study): a population-based prevalence study. Lancet, 370:741-50.

Calverley PM, Anderson JA, Celli B, et al. 2007. Salmeterol and fluticasone propionate and survival in chronic obstructive pulmonary disease. N Engl J Med, 356:775-89.

Calverley PM. 2000, Inhaled corticosteroids are beneficial in chronic obstructive pulmonary disease. Am J Respir Crit Care Med, 161:341-2.

Caramori G, Bettoncelli G, Tosatto R, et al. 2005. Underuse of spirometry by general practitioners for the diagnosis of COPD in Italy. Monaldi Arch Chest Dis, 63:6-12.

Cazzola M, Noschese P, Salzillo A, et al. 2005. Bronchodilator response to formoterol after regular tiotropium or to tiotropium after regular formoterol in COPD patients. Respir Med, 99:524-8.

Chavannes N, Schermer T, Akkermans R, et al. 2004. Impact of spirometry on GPs' diagnostic differentiation and decision-making. Respir Med, 98:1124-30.

Diaz-Lobato S, Mayoralas S, Buffels J. 2004. Underuse of spirometry in primary care. Chest, 126:1712.

Dowd LC, Fife D, Tenhave T, et al. 2003. Attitudes of physicians toward objective measures of airway function in asthma. Am J Med, 114:391-6.

Fauzi AR. 2003. Knowledge and practice of medical doctors on chronic obstructive pulmonary disease: a preliminary survey from a state hospital. Med J Malaysia, 58:205-12.

Freeman D, Nordyke RJ, Isonaka S, et al. 2005. Questions for COPD diagnostic screening in a primary care setting. Respir Med, 99:1311-18.

Fried RA, Miller RS, Green LA, et al. 2005. The use of objective measures of asthma severity in primary care: a report from ASPN. J Fam Pract, 41:139-43.

[GOLD] Global Initiative for Chronic Obstructive Lung Disease. 2007. From the Global Strategy for the Diagnosis, Management and Prevention of COPD, Global Initiative for Chronic Obstructive Lung Disease (GOLD) [online]. Accessed on December 19, 2007. URL: http://www. goldcopd.org/.

Garcia-Aymerich J, Escarrabill J, Marrades RM, et al. 2006. Differences in COPD care among doctors who control the disease: general practitioner vs pneumologist. Respir Med, 100:332-9.

[GSK] GlaxoSmithKline. 2007. Confronting COPD in America [online]. Accessed on December 19, 2007. URL: http://www.copdinamerica. com/index.html.

Halbert RJ, Isonaka S, George D, et al. 2003. Interpreting COPD Prevalence estimates: what is the true burden of disease? Chest, 123:1684-92.

Halbert RJ, Isonaka S. 2006. Internal Primary Care Respiratory Group (IPCRG) Guidelines: integrating diagnostic guidelines for managing chronic respiratory diseases in primary care. Prim Care Respir J, 15:13-19.

Hansen-Flaschen J. 2007. Effects of anticholinergics and beta-agonists in COPD. J Gen Intern Med, 22:893; author reply 894.

Hardie JA, Buist AS, Vollmer WM, et al. 2002. Risk of over-diagnosis of COPD in asymptomatic elderly never-smokers. Eur Respir J, $20: 1117-22$

Hurst JR, Wedzicha JA. 2007. What is (and what is not) a COPD exacerbation: thoughts from the new GOLD guidelines. Thorax, 62:198-9.
Kaminsky DA, Marcy TW, Bachand M, et al. 2005. Knowledge and use of office spirometry for the detection of chronic obstructive pulmonary disease by primary care physicians. Respir Care, 50:1639-48.

Kesten S, O'Donnell D. 2005. Improvements in symptom-limited exercise performance over $8 \mathrm{~h}$ with once-daily tiotropium in patients with COPD. Chest, 128:1168-78.

Levy ML, Fletcher M, Price DB, et al. 2006. International Primary Care Respiratory Group (IPCRG) Guidelines: diagnosis of respiratory diseases in primary care. Prim Care Respir J, 15:20-34.

Lindberg A, Eriksson B, Larsson LG, et al. 2006. Seven-year cumulative incidence of COPD in an age-stratified general population sample. Chest, 129:879-85.

Lusuardi M, De Benedetto F, Paggiaro P, et al. 2006. A randomized controlled trial on office spirometry in asthma and COPD in standard general practice: data from spirometry in Asthma and COPD: a comparative evaluation Italian study. Chest, 129:844-52.

Mannino DM, Buist AS. 2007. Global burden of COPD: risk factors, prevalence, and future trends. Lancet, 370:765-73.

Mannino DM. 2002. COPD: epidemiology, prevalence, morbidity and mortality, and disease heterogeneity. Chest, 121:121S-6S.

Meulepas MA, Jacobs JE, Lucas AE, et al. 2006. The feasibility of a primary care model for the management of COPD. Prim Care Respir J, $15: 337-41$

Mulcahy P, Buetow S, Osman L, et al. 2005. GPs' attitudes to discussing prognosis in severe COPD: an Auckland (NZ) to London (UK) comparison. Fam Pract, 22:538-40.

[NICE] National Institute for Health and Clinical Excellence. 2007. Welcome to the National Institute for Health and Clinical Excellence [online]. Accessed on August 14, 2007. URL: http://www.nice.org.uk/.

Nihlen U, Montnemery P, Lindholm LH, et al. 2003. Detection of chronic obstructive pulmonary disease (COPD) in primary health care: role of spirometry and respiratory symptoms. Scand J Prim Health Care, 48:1194-201.

[NLHEP] National Lung Health Education Program. 1998. Strategies in preserving lung health and preventing COPD and associated diseases. The National Lung Health Education Program (NLHEP). Chest, 113(2 Suppl):123S-163S

Pauwels RA, Buist AS, Ma P, et al. 2001. Global strategy for the diagnosis, management, and prevention of chronic obstructive pulmonary disease: National Heart, Lung, and Blood Institute and World Health Organization Global Initiative for Chronic Obstructive Lung Disease (GOLD): Executive summary. Respir Care, 46:798-825.

Paz-Diaz H, Montes de Oca M, Lopez JM, et al. 2007. Pulmonary rehabilitation improves depression, anxiety, dyspnea and health status in patients with COPD. Am J Phys Med Rehabil, 86:30-6.

Pena VS, Miravitlles M, Gabriel R, et al. 2000. Geographic variations in prevalence and underdiagnosis of COPD:results of the IBERPOC multicentre epidemiological study. Chest, 118:981-9.

Price DB, Tinkelman DG, Halbert RJ, et al. 2006. Symptom-based questionnaire for identifying COPD in smokers. Respiration, 73:285-95.

Ries AL, Bauldoff GS, Carlin BW, et al. 2007. Pulmonary rehabilitation: Joint ACCP/AACVPR Evidence-Based Clinical Practice Guidelines. Chest, 131(Suppl): 4S-42S.

Schermer TR, Jacobs JE, Chavannes NH, et al. 2003. Validity of spirometric testing in a general practice population of patients with chronic obstructive pulmonary disease. Thorax, 58:861-6.

Tinkelman DG, Price DB, Nordyke RJ, et al. 2007. COPD Screening efforts in primary care: what is the yield? Prim Care Respir J, 16:41-8.

[USPSTF] US Department of Health and Health Services. 2007. United States Preventive Services Task Force [online]. Accessed on December 19, 2007. URL: http://www.ahrq.gov/clinic/uspstfix.htm.

Van Noord JA, de Munck DR, Bantje TA, et al. 2000. Long-term treatment of chronic obstructive pulmonary disease with salmeterol and the additive effect of ipratropium. Eur Respir J, 15:878-85.

van Schayck CP, Halbert RJ, Nordyke RJ, et al. 2005. Comparison of existing symptoms-based questionnaires for identifying COPD in the general practice setting. Respirology, 10:323-33. 
Walker PP, Mitchell P, Diamantea F, et al. 2006. Effect of primary-care spirometry on the diagnosis and management of COPD. Eur Respir $J, 28: 945-52$.

Walters J, Hansen E, Mudge P, et al. 2005. Barriers to the use of spirometry in general practice. Aust Fam Physician, 34:201-3.

Wilt TJ, Niewoehner D, Kim C, et al. 2005. Use of spirometry for case finding, diagnosis and management of COPD. Evidence report/Technology Assessment 121. AHRQ Publication 5-E017-2. Rockville, MD.
Yawn BP, Enright PL, Lemanske RF Jr, et al. 2007. Spirometry can be done in family physicians' offices and alters clinical decsions in management of asthma and COPD. Chest, 132:1162-8.

Yawn, BP, Yawn RA. 2005. Spirometry testing education in medical schools: a missed opportunity? Primary Care Respir J, 14:21-4.

Zaas D, Wise R, Wiener C. 2004. Airway obstruction is common but unsuspected in patients admitted to a general medicine service. Chest, 125:106-11. 
